\title{
Oral implant rehabilitation in a young patient in the aesthetic Zone: 5-year case report follow up.
}

IMPLANT THERAPY

OUTCOMES, PROSTHETIC ASPECTS
PIMENTEL, Gonçalo; FRANCISCHONE, Carlos; MONTENEGRO, Alexandre; MENDES, Vivian; PINTO Henrique; TEMPONI, Kamila; OLIVEIRA, Rafael; MONTENEGRO, Silvana; GOMES, Priscila; FIAUX, Juliana. Brazilian Navy - Rio de Janeiro - BRAZIL

\section{Abstract}

Edentulism is usually associated with the aging patient. But, total or partial tooth loss also affects young patients, mainly as a result of trauma, decay, anodontia, or congenital and acquired jaw defects involving the alveolar processes. There has been hesitation to perform implant therapy for growing children. Little is known about the outcome of the osseointegration procedure in young patients, and until now, only a limited number of case presentations have been reported.

\section{Background and Aim}

The success of treatment of partial or totally edentulous patients with oral implants has beem the basis for extending the use of implants in young patients with primary or acquired dental absence. This is a clinical case report of a rehabilitation with osseointegrated implant in an adolescent female still undergoing bone growth. Such a procedure is found to be controversial in the Literature, due to reports of bone development complications.

The main problem is installing implants in teenagers is that maxilla and mandible still in bone development. When the treatment is done before the end of the patient's growth spurt, studies show that these implants don't follow the continuous and spontaneous eruption pattern of natural dentition and may cause defects in alveolar process.

\section{Methods and Materials}

A 14-year-old female patient underwent surgery for installation of osseointegrated implant in the region of element 11 after having fractured the cervical portion of the root. The fracture had a 6-year history of endodontic treatment and internal root resorption, all closely followed by the endodontics clinic. Extraction was performed with minimal trauma to preserve region's alveolus and soft tissues. Immediately, alveolus was drilled and an implant (Drive $\mathrm{CM}{ }^{\circledR}$ $4.3 \times 16.0 \mathrm{~mm}$ - Neodent) was installed positioned $2 \mathrm{~mm}$ below the alveolar bone crest with primary stability of $30 \mathrm{Ncm}$. Bone grafting regeneration with Bio-Oss $\AA$ (Geistlich) and Bio-Gide $\AA$ (Geistlich) was performed on the buccal region. The fractured tooth was used to make a temporary crown that was cemented onto the abutment in the same session. After one year of implant installation, a definitive metal ceramic crown was made. A 5 year follow-up was performed with clinical exam e periapical xray
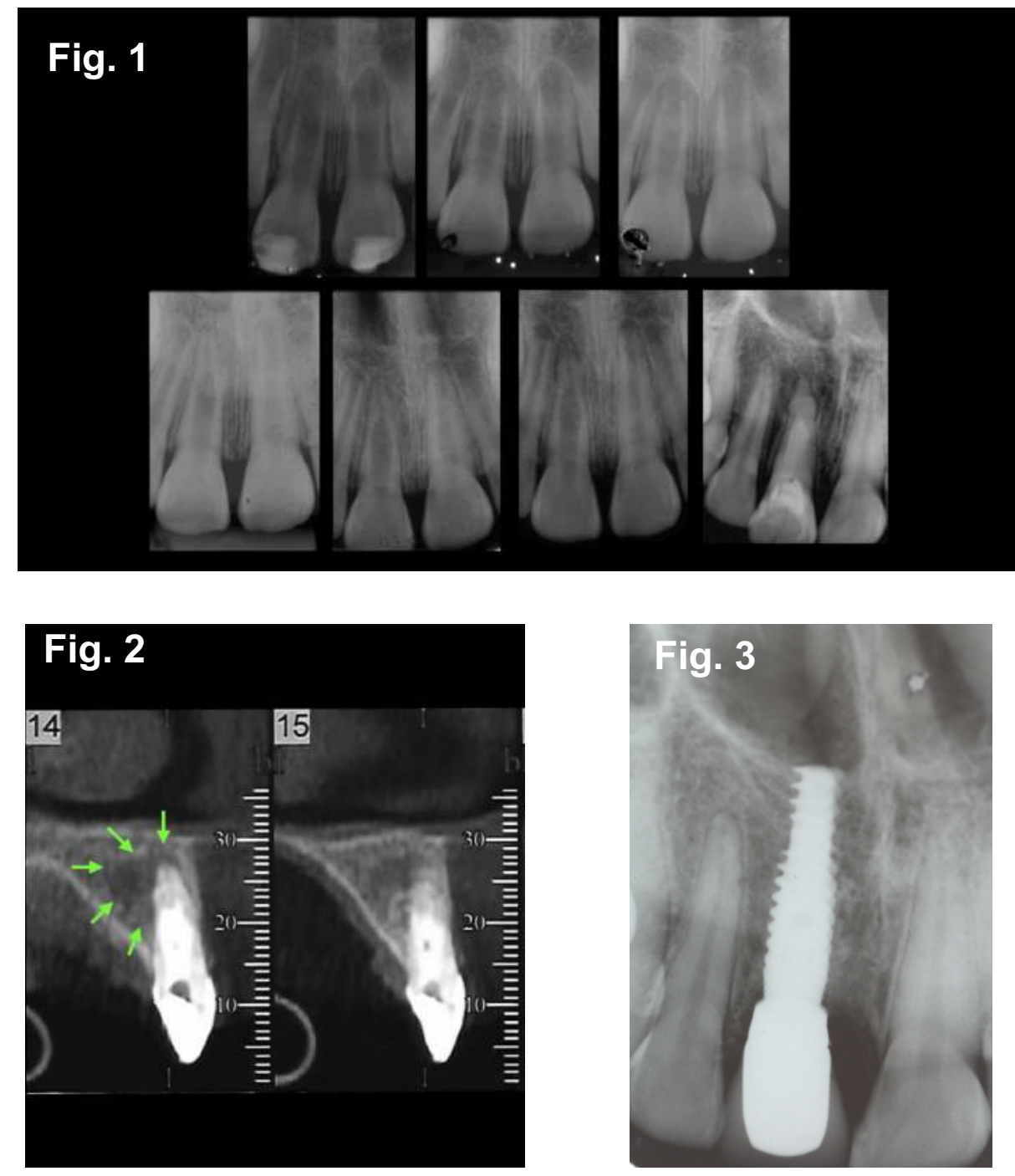

Figs. 1, 2 and 3 - radiological aspects

\begin{abstract}
Results
The case has been followed for 5 years, with photographic documentation every 6 months, to monitor the rehabilitation outcome
during the development of maxila. Results so far show a minor misalignment between the prosthetic implant crown and neighboring teeth, still with no complaints of aesthetic nature by the patient. The maintenance and health of soft and hard tissues around the implant has been achieved.
\end{abstract}
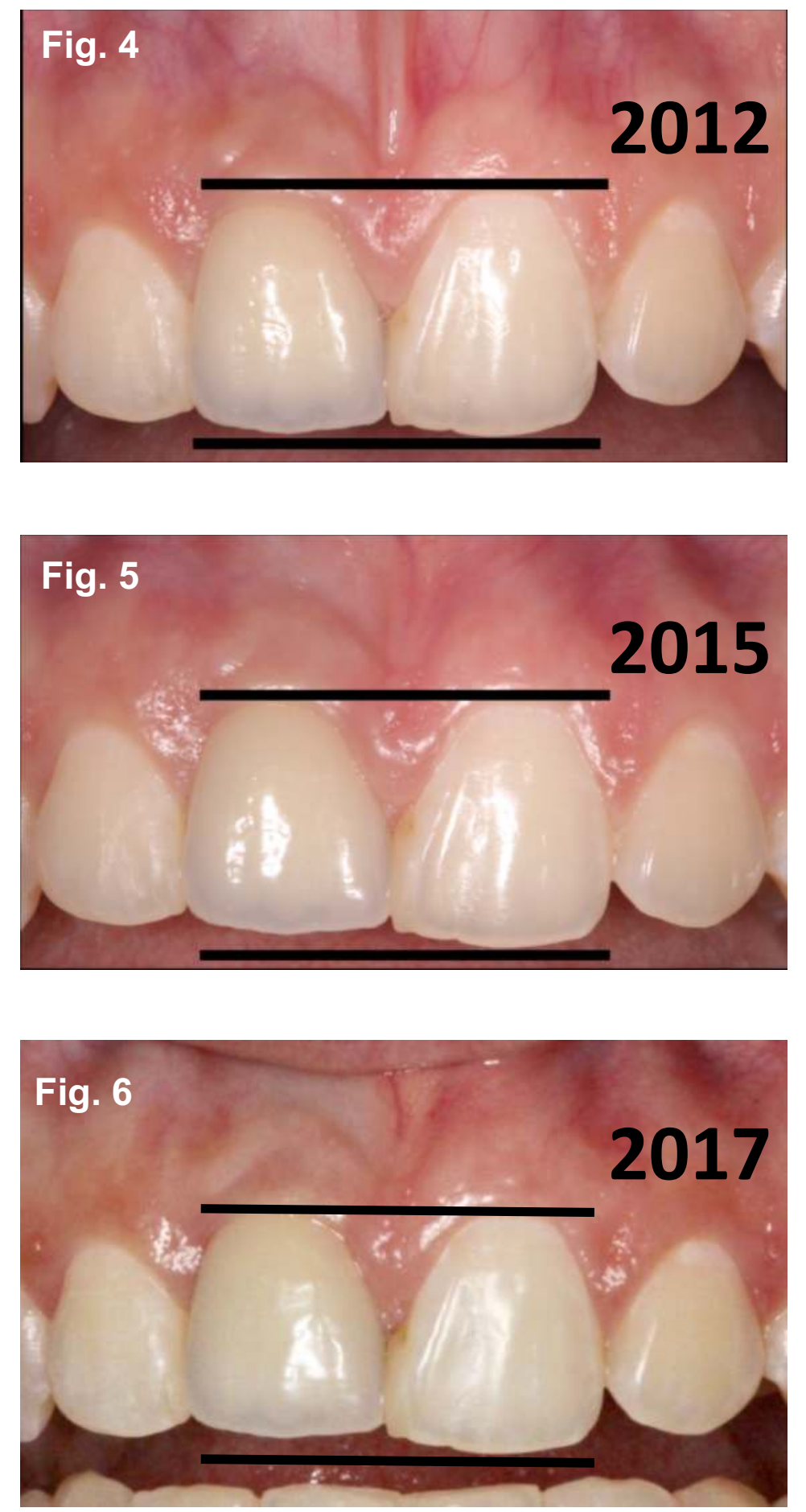

Figures 5, 5 and 6 - years follow up

\section{Conclusions}

Oral rehabilitation of growing child is considered a challenge. However, dental care is extremely important to provide them a better quality of life, ( ensuring better aesthetic, functional and psychological condilions. All of (n) and safety to the adolescent. And, until nowadays, no defects in the alveolar process have been observed due to the installation of the osseointegrated implant during the patient's growth phase. Only a small difference between the incisal edge of the crown compared to its homologue can be observed by photography, being imperceptible for the patient.

\section{References}

The Use of Osseointegrated Implants in Growing Jaws, Lekholm, U Int J Oral Maxillofac Implants. 1993;8(3):243-4

2. Osseointegrated Dental Implants in Growing Children: A Literature Review. Mankani, N. et al. Journal of Oral Implantology: October 2014, Vol. 40, No. 5, pp. 627-631.

3. Dental implants are a viable alternative for compensating oligodontia in adolescents. Heuberer, S, et al. Clinical Oral Imp. Res 2015 Apr;26(4).

4. Implant-Surgical and Prosthetic Reabilitation of Pacients with Multiple Dental Aplasia: a Clinical Report. WATZEK, G. The International Journal of Oral \& Maxilallofacial Implants, v. 14, n. 3, p. 417-423, Journal

5. Orthodontic aspects of the use of oral implants in adolescents: a 10year follow-up study. LEKHOLM, U. European Journal of Orthodontcs, v. 23, p. 715-731, 2001. 